\title{
OTR10 - CÉlulas-TRONCO ADULTAS HUMANAS PARA ENSAIOS DE CITOTOXICIDADE: UMA ALTERNATIVA AOS ENSAIOS ANIMAIS
}

\author{
Alessandra Melo de Aguiar ${ }^{1}$, Crisciele Kuligovski ${ }^{1}$, Elizabeth de Moraes ${ }^{1}$, Ana Paula \\ Abud $^{1}$, Jaiesa Zych ${ }^{1}$, Thamile Reus ${ }^{1}$, Bruno Dallagiovanna ${ }^{1}$ \\ ${ }^{1}$ Instituto Carlos Chagas, FIOCRUZ-PR
}

Objetivos: O objetivo desde estudo é desenvolver ensaios alternativos ao uso de animais e que tenham correlação com os efeitos tóxicos em humanos com o uso de células-tronco mesenquimais adultas humanas. Pretende-se assim investigar o uso de células-tronco em biotecnologia, ao testar sua aplicação em ensaios de citotoxicidade.

Métodos: Foi utilizada a metodologia de captação de vermelho neutro ("ICCVAMRecommended Test Method Protocol BALB/c 3T3 NRU Cytotoxicity Test Method," 2006). O ensaio de captação do vermelho neutro é um ensaio quantitativo da viabilidade celular que utiliza culturas primárias ou linhagens celulares estabelecidas. $\mathrm{O}$ efeito tóxico da substância teste é correlacionado com o decaimento da captação do vermelho neutro pelas células (ECCVAM). Este teste é recomendado pela OECD (OECD no 129, 2010 para estimativa de determinação das doses iniciais para teste de toxicidade oral aguda, entre outros. Este teste permite o cálculo do IC50 (dose de inibição do crescimento 50\%) utilizado para o cálculo da predição da DL50 (Dose Letal para 50\% dos animais).

Foram utilizadas células 3T3 como controle, em comparação com células-tronco mesenquimais de tecido adiposo e foram testadas 3 drogas, com diferentes graus de toxicidade, dada pela DL50: arsenito de sódio (classe 2, $5<\mathrm{DL} 50 \leq 5 \mathrm{mg} / \mathrm{kg}$ ), SDS (classe 4, 300mg $<$ DL50 $\leq 2000 \mathrm{mg} / \mathrm{kg}$ ) e glicerol (classe 6, DL50 $>5000 \mathrm{mg} / \mathrm{kg}$ ).

Resultados: A partir dos dados de IC50 obtidos para os diferentes substratos celulares avaliados, foi feita a extrapolação para o valor de LD50. Ao avaliar a predição dos valores de DL50 para as drogas avaliadas, houve concordância com a classificação de toxicidade para SDS e Glicerol e a classe de toxicidade foi subestimada em 1 classe para arsenito, onde foram classificadas como| classe 3, para ambos os substratos celulares utilizados. 
Desta forma, as células-tronco mesenquimais apresentam capacidade de predição da toxicidade semelhante a 3T3 para as drogas avaliadas.

Conclusão: As células-tronco mesenquimais apresentam capacidade de predição da toxicidade semelhante a 3T3 para as drogas avaliadas. É necessário realizar ensaio com um maior número de drogas de diferentes classes de toxicidade a fim de confirmar esses resultados. Os métodos desenvolvidos neste estudo tem grande potencial de aplicação para a indústria, pois podem ser utilizados para a avaliação de citotoxicidade de compostos químicos e de produtos já estabelecidos ou em desenvolvimento, com a redução ou substituição do uso de animais de laboratório e grande sensibilidade para predição da toxicidade em humanos. 